University of Nebraska - Lincoln

DigitalCommons@University of Nebraska - Lincoln

2012

\title{
Assembly of uniaxially aligned rare-earth-free nanomagnets
}

\author{
Balamurugan Balamurugan \\ University of Nebraska-Lincoln, balamurugan@unl.edu \\ Bhaskar Das \\ University of Nebraska-Lincoln, bhaskar.das@huskers.unl.edu \\ Shah R. Valloppilly \\ University of Nebraska-Lincoln, svalloppilly2@unl.edu \\ Ralph Skomski \\ University of Nebraska-Lincoln, rskomski2@unl.edu \\ Xingzhong Li \\ University of Nebraska-Lincoln, xli2@unl.edu
}

See next page for additional authors

Follow this and additional works at: https://digitalcommons.unl.edu/physicssellmyer

Part of the Physics Commons

Balamurugan, Balamurugan; Das, Bhaskar; Valloppilly, Shah R.; Skomski, Ralph; Li, Xingzhong; and Sellmyer, David J., "Assembly of uniaxially aligned rare-earth-free nanomagnets" (2012). David Sellmyer Publications. 241.

https://digitalcommons.unl.edu/physicssellmyer/241

This Article is brought to you for free and open access by the Research Papers in Physics and Astronomy at DigitalCommons@University of Nebraska - Lincoln. It has been accepted for inclusion in David Sellmyer Publications by an authorized administrator of DigitalCommons@University of Nebraska - Lincoln. 


\section{Authors}

Balamurugan Balamurugan, Bhaskar Das, Shah R. Valloppilly, Ralph Skomski, Xingzhong Li, and David J. Sellmyer 


\title{
Assembly of uniaxially aligned rare-earth-free nanomagnets
}

\author{
B. Balamurugan, ${ }^{1,2}$ B. Das, ${ }^{1,2}$ V. R. Shah, ${ }^{1}$ R. Skomski, ${ }^{1,2}$ X. Z. Li, ${ }^{1}$ and D. J. Sellmyer ${ }^{1,2, a)}$ \\ ${ }^{1}$ Nebraska Center for Materials and Nanoscience, University of Nebraska, Lincoln, Nebraska-68588, USA \\ ${ }^{2}$ Department of Physics and Astronomy, University of Nebraska, Lincoln, Nebraska-68588, USA
}

(Received 20 July 2012; accepted 4 September 2012; published online 19 September 2012)

\begin{abstract}
We report $\mathrm{HfCo}_{7}$ nanoparticles with appreciable permanent-magnet properties (magnetocrystalline anisotropy $K_{l} \approx 10 \mathrm{Mergs} / \mathrm{cm}^{3}$, coercivity $H_{c} \approx 4.4 \mathrm{kOe}$, and magnetic polarization $J_{s} \approx 10.9 \mathrm{kG}$ at $300 \mathrm{~K}$ ) deposited by a single-step cluster-deposition method. The direct crystalline-ordering of nanoparticles during the gas-aggregation process, without the requirement of a high-temperature thermal annealing, provides an unique opportunity to align their easy axes uniaxially by applying a magnetic field of about $5 \mathrm{kOe}$ prior to deposition, and subsequently to fabricate exchange-coupled nanocomposites having $J_{s}$ as high as $16.6 \mathrm{kG}$ by co-depositing soft magnetic Fe-Co. This study suggests $\mathrm{HfCo}_{7}$ as a promising rare-earth-free permanent-magnet alloy, which is important for mitigating the critical-materials aspects of rare-earth elements. (C) 2012 American Institute of Physics. [http://dx.doi.org/10.1063/1.4753950]
\end{abstract}

Magnetic nanoparticles of high magnetocrystalline anisotropy $K_{l} \geq 10 \mathrm{Mergs} / \mathrm{cm}^{3}$ and magnetic polarization $J_{s}$ above about $10 \mathrm{kG}\left(J_{s}=4 \pi M_{s}, M_{s}\right.$ is the saturation magnetization) are of interest for permanent magnets, recording media, and other significant applications. ${ }^{1-3}$ Such nanoparticle building-blocks are promising for improving magnetic properties by exploiting nanoscale effects and miniaturizing devices to suit modern technological requirements. ${ }^{4,5}$ Rareearth alloys and $L 1_{0}$-structure FePt and CoPt nanoparticles have superior permanent-magnet properties, ${ }^{6-8}$ but an everincreasing demand of rare-earth elements and the high cost of Pt intensify the search for rare-earth and Pt-free alloys. ${ }^{9,10}$ Another important problem is that generally nanoparticles have low remanent magnetization $M_{r}$ of only about $0.5 M_{s}$ due to the random distribution of easy axes and this limits potential use of nanoparticles in permanent magnets. ${ }^{2,11,12}$ However, the easy-axis alignment process for the improvement of $M_{r} / M_{s}$ using a magnetic field during the growth of nanoparticles is strongly hindered by the requirement of formation at high temperature (above $500^{\circ} \mathrm{C}$ ) for obtaining the desired crystalline ordering. ${ }^{13,14}$

In the present study, we have overcome the abovementioned problems by producing rare-earth-free permanentmagnet nanoparticles $\left(\mathrm{HfCo}_{7}\right)$ using a single-step gasaggregation-type cluster-deposition method without the requirement of a high-temperature thermal annealing and subsequently aligned their easy axes via applying a magnetic field, prior to deposition on substrates. Note that the $\mathrm{HfCo}_{7}$ intermetallic phase can play a key role in the ongoing search for alternative permanent-magnet alloys due to its high $T_{c}$ of about $600 \mathrm{~K}, J_{s}$ of above $10 \mathrm{kG}$, and non-cubic crystal structure. ${ }^{15-19}$ $\mathrm{The} \mathrm{HfCo}_{7}$ phase, however, forms only at a single composition (12.5 at. \% of $\mathrm{Hf}$ ) and temperatures as high above $1000^{\circ} \mathrm{C}$ under thermal equilibrium conditions. These limitations are major impediments in controlling the phase purity, crystalline ordering, and microstructure of bulk alloys, which affect their

\footnotetext{
${ }^{\text {a) }}$ Author to whom correspondence should be addressed. Electronic mail: dsellmyer@unl.edu.
}

permanent-magnet properies. ${ }^{15,16}$ In this regard, the nonequilibrium growth conditions of the cluster-deposition method are advantageous for the stabilization of metastable phases, and alloys requiring higher growth temperatures and with less symmetric crystal structures. ${ }^{6,20,21}$

The experimental setup used for depositing $\mathrm{HfCo}_{7}$ nanoparticles, as schematically shown in Fig. 1, consists of a cluster-formation chamber having a direct current (DC) magnetron plasma-sputtering discharge with a water-cooled gasaggregation chamber and a deposition chamber, where the substrate is kept at room temperature. ${ }^{6}$ The Co-Hf composite target was sputtered at a high DC magnetron sputtering power $\left(P_{d c}=200 \mathrm{~W}\right)$ using a mixture of argon ( $\left.\mathrm{Ar}\right)$ and helium (He) as sputtering gas to form $\mathrm{HfCo}_{7}$ nanoparticles in the gasaggregation chamber, which were extracted as a collimated beam moving towards the substrate. Nanoparticles were deposited on single crystalline $\mathrm{Si}(001)$ substrates for superconducting quantum interference device (SQUID) magnetometer, energy dispersive $\mathrm{x}$-ray analysis (EDX, JEOL JSM 840 A scanning electron microscope), and $\mathrm{x}$-ray diffraction (XRD, Rigaku D/Max-B diffractometer) measurements. Carboncoated copper grids were used as substrates for transmission electron microscopy (TEM, JEOL 2010 with an acceleration voltage of $200 \mathrm{kV}$ ) studies. For the fabrication of $\mathrm{HfCo}_{7}: \mathrm{Fe}-$ $\mathrm{Co}$ nanocomposites, $\mathrm{HfCO}_{7}$ nanoparticles were co-deposited along with soft $\mathrm{Fe}_{\mathrm{x}} \mathrm{Co}_{1-\mathrm{x}}$ phase $(\mathrm{x}=0.65)$ produced using another $\mathrm{dc}$ magnetron sputtering gun employed in the

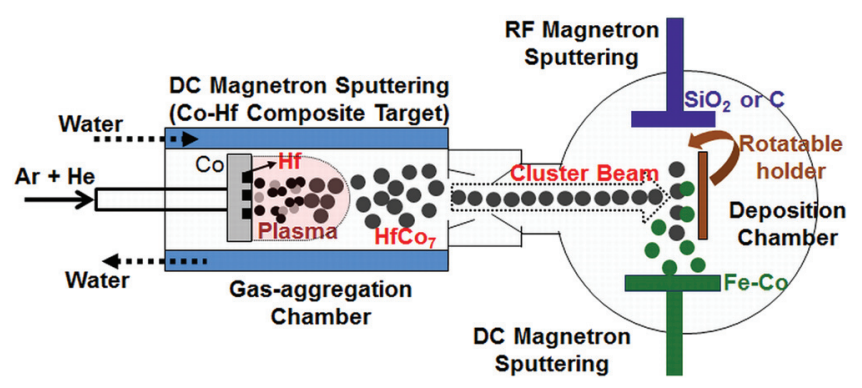

FIG. 1. A schematic illustration of the gas-aggregation-type cluster-deposition method used for the growth of $\mathrm{HfC}_{7}$ nanoparticles. 
deposition chamber as shown in Fig. 1. During the deposition of nanocomposites, the substrate holder was rotated by about $20^{\circ}$ to face both cluster beam and Fe-Co flux. The volume fraction of the soft phase was controlled by varying the deposition rate of $\mathrm{HfCO}_{7}$ nanoparticles and Fe-Co. Nanoparticle samples were coated with a protective cap layer (about $3 \mathrm{~nm}$ ) such as $\mathrm{SiO}_{2}$ immediately after deposition using a RF sputtering gun employed in the deposition chamber.

We have deposited two types of nanoparticle samples: (i) randomly oriented nanoparticles in the absence of a magnetic field (labeled as unaligned nanoparticles) and oriented nanoparticles by applying a magnetic field to nanoparticles using a set of permanent magnets before deposition (labeled as aligned nanoparticles), which will be discussed later. We also have prepared bulk $\mathrm{HfCo}_{7}$ alloys for comparing the structural and magnetic properties of nanoparticles. For this, high-purity $\mathrm{Co}$ and $\mathrm{Hf}$ of compositions corresponding to $\mathrm{HfCO}_{7}$ (12.5 at. $\%$. of $\mathrm{Hf}$ ) were mixed homogeneously using a conventional arc-melting method and subsequently melt spun to obtain bulk $\mathrm{HfCo}_{7}$ ribbons. The rapid cooling during the melt spinning process is advantageous to have good control over the phase purity and microstructure in the bulk $\mathrm{HfCo}_{7}$ alloys.

XRD measurements were used to investigate the crystal structure of $\mathrm{HfCo}_{7}$. Note that the bulk $\mathrm{HfCo}_{7}$ is reported to form one of the following structures: tetragonal or orthorhombic. ${ }^{15,17-19}$ In the present study, we first used TOPAS (Total Pattern Analysis Solution, Bruker AXS) to index the XRD pattern of the bulk $\mathrm{HfCo}_{7}$ alloys (curve (i) in Fig. 2(a)) by assuming the above-mentioned crystal structures. The positions of the experimental XRD peaks (curve (i) in Fig. 2(a)) show good agreement with the XRD peak positions using TOPAS (black-dotted vertical lines in Fig. 2(a)) for an orthorhombic structure having lattice parameters of about $a=4.7189 \AA ; \quad b=4.2783 \AA$, and $c=8.0705 \AA$. Similarly, the XRD pattern of the unaligned $\mathrm{HfCo}_{7}$ nanoparticles (curve (ii) in Fig. 2(a)) shows the most intense diffraction peaks corresponding to (002), (200), and (202) as observed in the case of bulk $\mathrm{HfCo}_{7}$ alloys.

Some of the low-intensity diffraction peaks are weak or not visible in the XRD pattern of the unaligned $\mathrm{HfCo}_{7}$ nanoparticles (curve (ii) in Fig. 2(a)) due to comparatively low absolute intensities. In addition, the diffraction peaks corresponding to (202) and (004) separated only by a small angular position are indistinguishable due to their breadth resulting from the nanoparticle size. Generally, the clusterdeposition method produces assemblies of single-crystalline nanoparticles of average particle size $d \leq 15 \mathrm{~nm}$ with an rms standard deviation of $\sigma / \mathrm{d} \leq 0.20$ and this depends on the gas flow rates, gas-aggregation length, and $P_{d c}{ }^{6}$ The size $\mathrm{d}$ for $\mathrm{HfCo}_{7}$ nanoparticles was varied from about 4.8 to $12 \mathrm{~nm}$ by varying the flow rate of $\operatorname{Ar}$ (200 to 500 SCCM (standard cubic centimeter per minute)) and/or gas aggregation length (10 to $15 \mathrm{~cm})$, while keeping $P_{d c}(200 \mathrm{~W})$ and flow rate of $\mathrm{He}(100 \mathrm{SCCM})$ as constants. For example, in the present study, TEM image of $\mathrm{HfCo}_{7}$ nanoparticles (Fig. 2(b)) and corresponding particle-size histogram (inset of Fig. 2(b)) reveal $\mathrm{d}=8.3 \mathrm{~nm}$ and $\sigma / \mathrm{d}=0.19$.

Magnetic properties of unaligned $\mathrm{HfCO}_{7}$ nanoparticles were investigated by measuring the magnetization $M$ as a function of applied magnetic field $H$ from -70 to $70 \mathrm{kOe}$
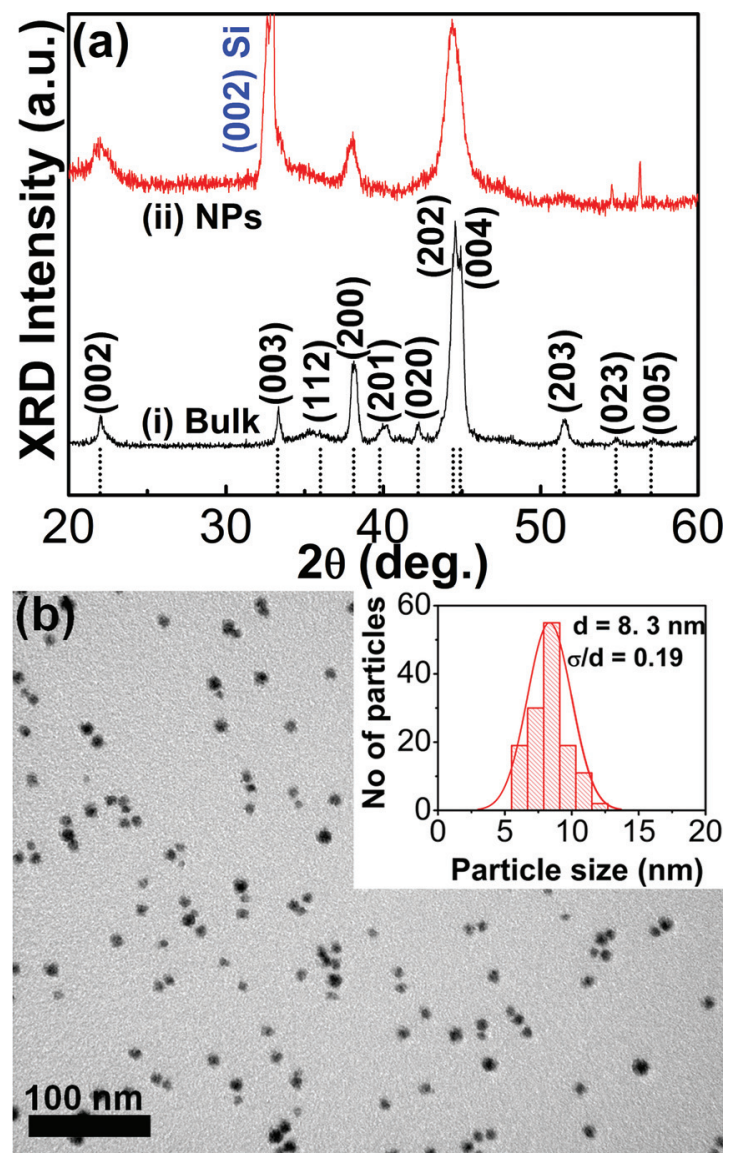

FIG. 2. (a) X-ray diffraction patterns of bulk $\mathrm{HfCo}_{7}$ and unaligned $\mathrm{HfCo}_{7}$ nanoparticles (NPs), where the estimated XRD peak positions corresponding to the orthorhombic structure using TOPAS are shown as black-dotted vertical lines. (b) Transmission electron microscope image of NPs. The corresponding particle-size histogram is given as an inset, where $\sigma$ and $\mathrm{d}$ are the standard deviation and average particle size, respectively.

and also compared with that of bulk $\mathrm{HfCo}_{7}$ alloys. $\mathrm{HfCo}_{7}$ nanoparticles with $\mathrm{d}=4.8 \mathrm{~nm}$ exhibit superparamagnetic behavior by showing a coercivity $H_{c}=0$ at $300 \mathrm{~K}$ and blocking temperature of about $140 \mathrm{~K}$ in the zero-field-cooled magnetization curve (not shown here) and those having $\mathrm{d}>5 \mathrm{~nm}$ always show ferromagnetic behavior. For example, $M-H$ curves of the unaligned $\mathrm{HfCo}_{7}$ nanoparticles having $\mathrm{d}=8.3 \mathrm{~nm}$ measured at $10 \mathrm{~K}$ (blue curve) and $300 \mathrm{~K}$ (red curve) are shown along with the room-temperature $M-H$ curve of the bulk $\mathrm{HfCo}_{7}$ alloys (black curve) in Fig. 3(a). These results provide two important observations. First, $M$ of both unaligned $\mathrm{HfCo}_{7}$ nanoparticles and bulk alloys in Fig. 3(a) does not attain complete saturation even at $H=70 \mathrm{kOe}$, revealing a large value of magnetic anisotropy. The magnetic anisotropy constant $K_{l}$ was estimated by fitting the high field region of $M-H$ curves using the law of approach to saturation method, widely used for randomly oriented nanoparticles. ${ }^{12,22-24}$ This behavior is consistent with the observation of $M_{r} / M_{s}$ of about 0.5 and nearly identical room-temperature in-plane and out-of-plane $M-H$ curves of the unaligned $\mathrm{HfCo}_{7}$ nanoparticles (not shown here).

The magnetization for random-anisotropy magnets near saturation $\left(M_{s}\right)$ can be estimated from

$$
M=M_{\mathrm{s}}\left(1-A / H^{2}\right)+\chi H .
$$



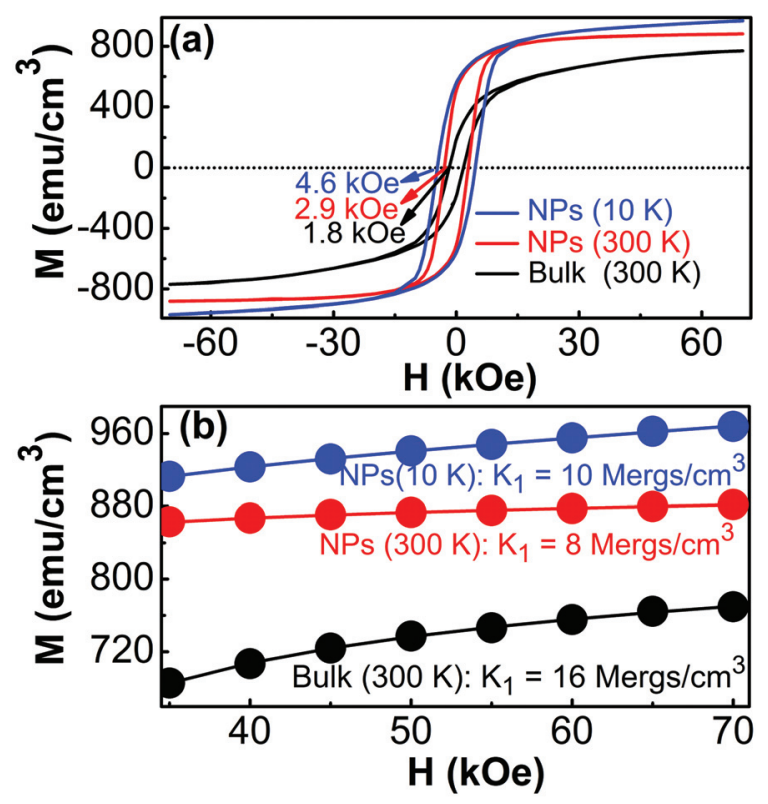

FIG. 3. (a) $M-H$ curves of the unaligned $\mathrm{HfCo}_{7} \mathrm{NPs}$ measured at $10 \mathrm{~K}$ and $300 \mathrm{~K}$ and bulk alloy measured at $300 \mathrm{~K}$. (b) An estimation of magnetic anisotropy constant $K_{l}$ from the high-field region of $M$ vs. $H$ curves using the law of approach to saturation method (see Refs. 12 and 22-24). The solid spheres and lines represent the corresponding experimental data and fitting, respectively.

In Eq. (1), $\chi$ is the high-field susceptibility and the constant $A$ depends on the anisotropy constant $K_{1}$ as given by

$$
A=\frac{4}{15} \frac{K_{1}^{2}}{M_{s}^{2}} .
$$

The high-field region of $M(H \geq 30 \mathrm{kOe})$ in Fig. 3(a) is fitted using Eq. (1) to estimate $K_{l}$ as shown in Fig. 3(b), where the experimental and fitted data are represented by solid spheres and lines, respectively. This evaluation shows that both $\mathrm{HfCo}_{7}$ nanoparticles and bulk alloys have high anisotropies of about $10 \mathrm{Mergs} / \mathrm{cm}^{3}$ as indicated in Fig. 3(b). $\mathrm{HfCo}_{7}$ nanoparticles have a lower $K_{l}$ than bulk, presumably due to disorder and surface effects in nanoparticles. ${ }^{11}$ Second, $\mathrm{HfCo}_{7}$ nanoparticles exhibit $H_{c}$ of $4.6 \mathrm{kOe}$ at $10 \mathrm{~K}$ and $2.9 \mathrm{kOe}$ at $300 \mathrm{~K}$ and $J_{s}$ of about $10.9 \mathrm{kG}$, which are comparable with those of reported rare-earth alloy nanoparticles. ${ }^{7,25-29}$ In addition, the room-temperature coercivity of $\mathrm{HfCo}_{7}$ nanoparticles $(2.9 \mathrm{kOe})$ is higher than that of bulk $\mathrm{HfCo}_{7}$ alloys $(1.8$ $\mathrm{kOe})$. In contrast, Co nanoparticles and bulk metal exhibit $H_{c}$ less than $50 \mathrm{Oe}$ and a low $K_{1}$ of about $5 \mathrm{Mergs} / \mathrm{cm}^{3}$ (not shown here).

In the present study, $\mathrm{HfCo}_{7}$ nanoparticles gain sufficient energy for crystallization from the collisions with the ions during the gas-aggregation process ${ }^{20,21,30}$ and form the desired high-anisotropy crystal structure without a subsequent hightemperature annealing, which is normally required in the case of permanent-magnet alloys and nanoparticles. ${ }^{7,8}$ Thus, it is possible to fabricate exchange-coupled nanocomposites using co-deposition method as discussed earlier without modifying the crystal structure, phase purity, and particle size of $\mathrm{HfCo}_{7}$ nanoparticles. A Fe-Co target with $\mathrm{Fe}_{65} \mathrm{Co}_{35}$ composition (which has a high $J_{s}$ of about $24 \mathrm{kG}$ ) was used to deposit FeCo soft phase. XRD pattern and $M-H$ curve of the soft Fe-Co
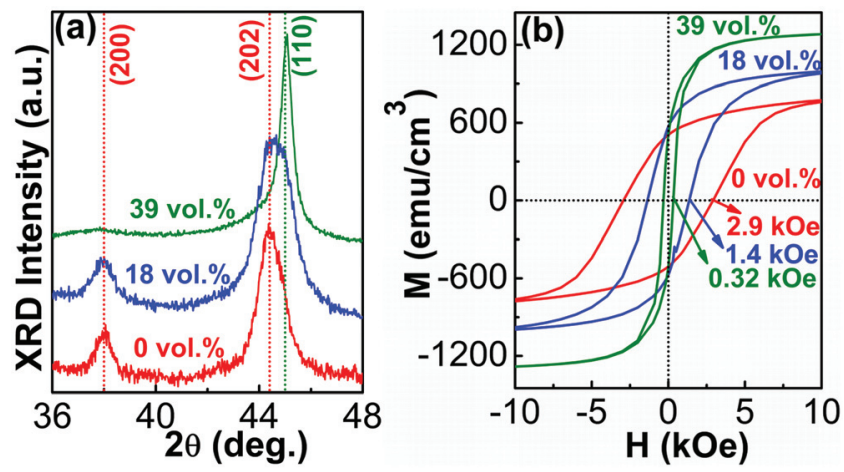

FIG. 4. The unaligned exchanged-coupled $\mathrm{HfCo}_{7}: \mathrm{Fe}-\mathrm{Co}$ nanocomposites with different volume fractions (vol. \%) of soft Fe-Co phase: (a) X-ray diffraction patterns, where the red and green-dotted vertical lines represent the standard positions of diffraction peaks corresponding to $\mathrm{HfCo}_{7}$ and $\mathrm{Fe}-\mathrm{Co}$, respectively. (b) The expanded room-temperature $M-H$ curves.

layer deposited in the absence of nanoparticle beam showed a body-centered cubic structure and soft magnetic properties: $H_{c}=52 \mathrm{Oe}, J_{s}=22.5 \mathrm{kG}$, and $M_{r} / M_{s}=0.79$ at $300 \mathrm{~K}$, respectively (not shown here).

The exchange coupling of hard magnetic nanoparticles with soft magnetic phases is expected to improve $J_{s}{ }^{31-36}$ XRD patterns and expanded room-temperature $M-H$ curves of unaligned $\mathrm{HfCo}_{7}: \mathrm{Fe}-\mathrm{Co}$ nanocomposites having 0 , 18, and 39 vol. \% of soft Fe-Co phase are shown in Figs. 4(a) and 4(b), respectively. The variation of the Fe-Co soft phase in these nanocomposite samples is clearly evident from the changes in the relative intensities of XRD peaks corresponding to $\mathrm{Fe}-\mathrm{Co}$ and $\mathrm{HfCo}_{7}$ nanoparticles as shown in Fig. 3(a). The position of diffraction peaks corresponding to (200) and (202) of orthorhombic $\mathrm{HfCo}_{7}$ and (110) of bcc FeCo are indicated by red and green-dotted vertical lines, respectively in Fig. 4(a). As compared to (200) and (202) diffraction peaks of $\mathrm{HfCo}_{7}$ nanoparticles, the XRD peak corresponding to (110) of bcc Fe-Co is comparably intense for $18 \mathrm{vol}$. \% of $\mathrm{Fe}-\mathrm{Co}$ (blue curve) and becomes dominant on increasing $\mathrm{Fe}-$ Co content to 39 vol. \% of Fe-Co (green curve) as shown in Fig. 4(a). Higher-resolution TEM images clearly show that $8.3 \mathrm{~nm} \mathrm{HfCO}_{7}$ nanoparticles are coated and surrounded by Fe-Co phase (not shown here).

The room-temperature $M-H$ curve of unaligned $\mathrm{HfCo}_{7}$ nanoparticles show $H_{c}=2.9 \mathrm{kOe}$ and $J_{s}=10.9 \mathrm{kG}$ at $300 \mathrm{~K}$ (red curve in Fig. 4(b)). $\mathrm{HfCo}_{7}: \mathrm{Fe}-\mathrm{Co}$ nanocomposites show an increase in $J_{s}$ from $13.6 \mathrm{kG}$ to as high as $16.6 \mathrm{kG}$ on increasing $\mathrm{Fe}-\mathrm{Co}$ fractions from 18 to 39 vol. \%, but they exhibit decreasing $H_{c}$ values of 1.4 and $0.32 \mathrm{kOe}$ for 18 vol. $\%$ and 39 vol. \% of Fe-Co, respectively as shown in Fig. 4(b). In ideal exchange-coupled nanocomposites, magnetic moments in both hard and soft phases are expected to switch coherently and the resultant $H_{c}$ and $J_{s}$ will be some average of the constituent phases. $H_{c}$ is, however, expected to reduce substantially for nanocomposites having more than $20 \mathrm{vol}$. \% of soft phase due to the propagation of domain walls. ${ }^{31-36}$

Although unaligned $\mathrm{HfCo}_{7}$ nanoparticles and $\mathrm{HfCo}_{7}: \mathrm{Fe}-$ Co nanocomposites have shown appreciable permanentmagnet properties, they exhibit a low $M_{r} / M_{s}$ of about 0.5 due to the random distribution of easy axes. The isotropic nature of the hard phase has been observed to affect the energy products of nanocomposite permanent magnets. ${ }^{31-33}$ For example, 
(a)
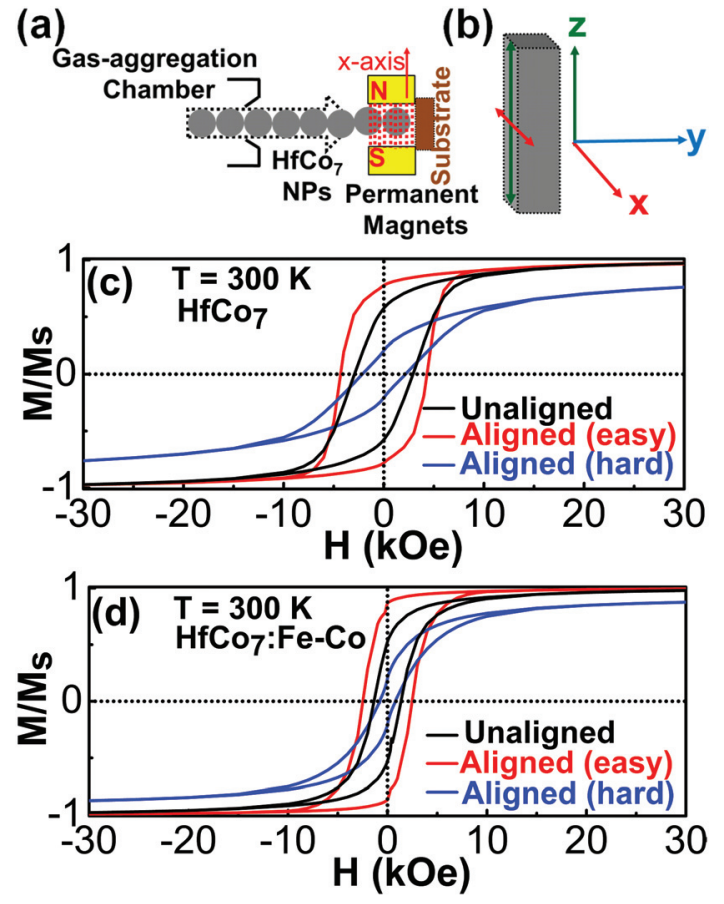

FIG. 5. Easy-axis alignment of $\mathrm{HfCo}_{7}$ nanoparticles (NPs): (a) Schematic illustration of the alignment method using a set of permanent magnets (NS), prior to deposition on substrate, where the sputtering guns used for depositing Fe-Co soft phase and cap layer are not shown here. (b) Three dimensional view of the substrate is also given-in order to show the direction of the applied magnetic field (x-axis) used for alignment with respect to the substrate plane. The expanded room-temperature $M-H$ curves of the aligned NPs measured along the easy ( $\mathrm{x}$-axis) and hard (y-axis) directions for (c) $\mathrm{HfCo}_{7} \mathrm{NPS}$ and (d) $\mathrm{HfCo}_{7}$ :Fe-Co nanocomposites with 18 vol. \% of $\mathrm{Fe}-\mathrm{Co}$, whereas the $M-H$ curves for the corresponding unaligned samples also are given for comparison.

the isotropic exchange-coupled $\mathrm{Fe}-\mathrm{Pt}$ and $\mathrm{Sm}-\mathrm{Co}-$ based nanocomposite magnets show $(\mathrm{BH})_{\max }$ of about 20 MGOe, which is lower than the theoretical value of anisotropic $\mathrm{Nd}_{2} \mathrm{Fe}_{14} \mathrm{~B}$ - based magnets (58 MGOe) and preferentially textured FePt-based composite thin films deposited on $\mathrm{MgO}$ substrates (54 MGOe). ${ }^{31-33,37}$ In the case of nanoparticles, the requirement of high temperatures for obtaining the crystalline ordering of the hard phase hinders the easy-axis alignment process using a magnetic field. For example, thermal annealing of soft FePt nanoparticles having disordered face center cubic structure in a very large magnetic field to produce hard $L 1_{O}$-ordering with aligned easy axes was unsuccessful, presumably due to the fact that the temperature required for higher ordering is above Curie temperature $T_{c} .{ }^{13,14}$

Since nanoparticle growth and crystallization of $\mathrm{HfCo}_{7}$ nanoparticles occur directly during the gas-aggregation process in the present study, it is possible to align the easy axes by applying a magnetic field to $\mathrm{HfCo}_{7}$ nanoparticles with a set of permanent magnets before deposition as shown in Fig. 5(a). By considering the substrate as a reference plane as shown in Fig. 5(b), $\mathrm{HfCo}_{7}$ nanoparticles travel for a distance of $10 \mathrm{~mm}$ under the influence of a magnetic field of about 5 kOe applied along the $\mathrm{x}$-axis, before landing on the substrate. In the present study, we have measured room-temperature $M-H$ curves of two types of magnetically aligned samples: pure $\mathrm{HfCo}_{7}$ nanoparticles (Fig. 5(c)) and $\mathrm{HfCo}_{7}: \mathrm{Fe}-\mathrm{Co}$ nanocomposites with 18 vol. \% of Fe-Co (Fig. 5(d)). For comparison, $M-H$ curves of the unaligned $\mathrm{HfCo}_{7}$ and $\mathrm{HfCo}_{7}: \mathrm{Fe}-\mathrm{Co}$
TABLE I. Comparison of $H_{c}$ and $M_{r} / M_{s}$ at $300 \mathrm{~K}$ measured along easy (x-axis) and hard (y-axis) directions of the magnetically aligned $\mathrm{HfCo}_{7}$ nanoparticles and $\mathrm{HfCo}_{7}$ : $\mathrm{Fe}-\mathrm{Co}$ nanocomposites.

\begin{tabular}{lcc}
\hline \hline Sample & $H_{c}$ (kOe) & $M_{r} / M_{s}$ \\
\hline Aligned $\mathrm{HfCo}_{7}$ & 4.4 (easy) & 0.78 (easy) \\
& 1.9 (hard) & 0.21 (hard) \\
Unaligned $\mathrm{HfCo}_{7}$ & 2.9 & 0.57 \\
Aligned $\mathrm{HfCo}_{7}: \mathrm{Fe}-\mathrm{Co}$ & 2.5 (easy) & 0.87 (easy) \\
& 0.8 (hard) & 0.21 (hard) \\
Unaligned $\mathrm{HfCo}_{7}: \mathrm{FeCo}$ & 1.4 & 0.53 \\
\hline \hline
\end{tabular}

with 18 vol. \% of Fe-Co are also shown in Figs. 5(c) and 5(d), respectively.

$H_{c}$ and $M_{r} / M_{s}$ estimated from Figs. 5(c) and 5(d) are summarized in Table I. These results show an increase in $H_{c}$ and $M_{r} / M_{s}$ along the easy axis (x-axis) and a substantial reduction of those values along the hard axis (y-axis) in the aligned samples. Note that $M-H$ loop of the aligned samples measured along the $\mathrm{z}$-axis is identical to that measured along $y$-axis (not shown here). These results reveal an effective uniaxial alignment upon applying a magnetic field to $\mathrm{HfCo}_{7}$ nanoparticles prior to deposition. We also have estimated the magnetic anisotropy constant by using the area under the complete $M-H$ curves (from 0 to $70 \mathrm{kOe}$ ) of the aligned $\mathrm{HfCo}_{7}$ nanoparticles along the easy and hard axes, ${ }^{38}$ and this analysis yields a value of $9.0 \mathrm{Mergs} / \mathrm{cm}^{3}$, in close agreement with $8.0 \mathrm{Mergs} / \mathrm{cm}^{3}$ determined from the approach to saturation method. As shown in Table I, $H_{c}$ and $M_{r} / M_{s}$ of the aligned $\mathrm{HfCo}_{7}$ and $\mathrm{HfCo}_{7}: \mathrm{Fe}-\mathrm{Co}$ samples measured along the easy axis are also higher than that of the corresponding unaligned samples.

In conclusion, we have succeeded in producing uniaxially aligned $\mathrm{HfCo}_{7}$ nanoparticles and $\mathrm{HfCo}_{7}$ :Fe-Co nanocomposites at room temperature using a single-step cluster-deposition method. Structural analysis indicates that $\mathrm{HfCO}_{7}$ likely crystallizes in the orthorhombic structure. $\mathrm{HfCo}_{7}$ nanoparticles exhibit $H_{c}(4.4 \mathrm{kOe}), K_{l}\left(\sim 10 \mathrm{Mergs} / \mathrm{cm}^{3}\right)$, and $J_{s}(10.8 \mathrm{kG})$ at $300 \mathrm{~K}$, which are comparable with the magnetic properties of rare-earth alloy nanoparticles. An enhancement of $J_{s}$ to as high as $16.6 \mathrm{kG}$ was observed in $\mathrm{HfCo}_{7}: \mathrm{Fe}-\mathrm{Co}$ nanocomposites on varying $\mathrm{Fe}-\mathrm{Co}$ concentration to 39 vol. \%, although the coercivity is reduced as compared to $\mathrm{HfCo}_{7}$ nanoparticles. This methodology also can be adopted easily to produce aligned nanoparticles of additional permanent-magnet alloys. The direct crystalline-ordering, in situ easy-axis alignment, and nanocomposite fabrication reported in the present study are important processing steps towards fabricating nanoparticle assemblies for next-generation nanocomposite magnets with improved performance.

This work is supported by Advanced Research Projects Agency-Energy (Grant No. DE-AR 0000046, B.B. and B.D.), US Department of Energy (Grant No. DE-FG02-04ER46152, D.J.S.), NSF-Materials Research Science and Engineering Center (Grant No. DMR-0820521, R.S.), and Nebraska Center for Materials and Nanoscience (V.R.S. and X.Z.L.). Thanks are due to Jeff Shield, Damien LeRoy, Z. Sun, and P.K. Sahota for helpful discussions. 
${ }^{1}$ N. A. Frey, S. Peng, K. Cheng, and S. Sun, Chem. Soc. Rev. 38, 2532 (2009).

${ }^{2}$ B. Balamurugan, D. J. Sellmyer, G. C. Hadjipanayis, and R. Skomski, Scr. Mater. 67, 542 (2012).

${ }^{3}$ D. Weller and T. McDaniel in Advanced Magnetic Nanostructures, edited by D. J. Sellmyer and R. Skomski (Springer, Berlin, 2006), p. 295.

${ }^{4}$ G. Reiss and A. Hütten, Nature Mater. 4, 725 (2005).

${ }^{5}$ D. J. Sellmyer, Nature (London) 420, 374 (2002).

${ }^{6}$ B. Balasubramanian, R. Skomski, X. Z. Li, S. R. Valloppilly, J. E. Shield, G. C. Hadjipanayis, and D. J. Sellmyer, Nano. Lett. 11, 1747 (2011).

${ }^{7}$ S. Sun, C. B. Murray, D. Weller, L. Folks, and A. Moser, Science 287, 1989 (2000).

${ }^{8}$ D. Alloyeau, C. Ricolleau, C. Mottet, T. Oikawa, C. Langlois, Y. Le Bouar, N. Braidy, and A. Loiseau, Nature Mater. 8, 940 (2009).

${ }^{9}$ N. Jones, Nature (London) 472, 22 (2011).

${ }^{10}$ R. Skomski, J. E. Shield, and D. J. Sellmyer, Magnetic Technology International (UKIP Media and Events Ltd., 2011), p. 26.

${ }^{11}$ Y. Xu, M. L. Yan, J. Zhou, and D. J. Sellmyer, J. Appl. Phys. 97, $10 J 320$ (2005).

${ }^{12}$ E. Kneller, Ferromagnetism (Springer, Berlin, 1962).

${ }^{13}$ S. Kang, Z. Jia, S. Shi, D. E. Nikles, and J. W. Harrell, Appl. Phys. Lett. 86, 062503 (2005).

${ }^{14}$ S. Kang, S. Shi, Z. Jia, G. B. Thompson, D. E. Nikles, J. W. Harrell, D. Li, N. Poudyal, V. Nandwana, and J. P. Liu, J. Appl. Phys. 101, 09J113 (2007).

${ }^{15}$ K. H. J. Buschow, J. Appl. Phys. 53, 7713 (1982).

${ }^{16}$ Y. Shimada and H. Kojima, J. Appl. Phys. 53, 3156 (1982).

${ }^{17}$ B. G. Demczyk and S. F. Cheng, J. Appl. Cryst. 24, 1023 (1991).

${ }^{18}$ S. C. Bedi and M. Forker, Phys. Rev. B 22, 14948 (1993).

${ }^{19}$ H. Okamoto, Phase Diagram of Binary Alloys (ASM, Materials Park, 2000), p. 248.

${ }^{20}$ H. Haberland, M. Karrais, M. Mall, and Y. Thurner, J. Vac. Sci. Technol. A 10, 3266 (2000).

${ }^{21}$ J. M. Qiu, J. Bai, and J. P. Wang, Appl. Phys. Lett. 89, 222506 (2006).
${ }^{22}$ G. C. Hadjipanayis, D. J. Sellmyer, and B. Brandt, Phys. Rev. B 23, 3349 (1981).

${ }^{23}$ A. Franco, Jr. and F. C. E. Silva, Appl. Phys. Lett. 96, 172505 (2010).

${ }^{24}$ X. Liu, J. Bai, F. Wei. Z. Yang, S. Takei, A. Morisako, and M. Matsumoto, J. Appl. Phys. 87, 6875 (2000).

${ }^{25}$ V. M. Chakka, B. Altuncevahir, Z. Q. Jin, and J. P. Liu, J. Appl. Phys. 99, 08E912 (2006).

${ }^{26}$ T. Matsushita, T. Iwamoto, M. Inokuchi, and N. Toshima, Nanotechnology 21, 095603 (2010).

${ }^{27}$ B. Balamurugan, R. Skomski, X. Z. Li, G. C. Hadjipanayis, and D. J. Sellmyer, J. Appl. Phys. 111, 07B527 (2012).

${ }^{28}$ C. H. Chen, S. J. Knutson, Y. Shen, R. A. Wheeler, J. C. Horwath, and P. N. Barnes, Appl. Phys. Lett. 99, 012504 (2011).

${ }^{29}$ N. G. Akdogan, G. C. Hadjipanayis, and D. J. Sellmyer, Nanotechnology 21, 295705 (2010).

${ }^{30}$ M. M. Patterson, A. Cochran, J. Ferina, X. Rui, T. A. Zimmerman, Z. Sun, M. J. Kramer, D. J. Sellmyer, and J. E. Shield, J. Vac. Sci. Technol. B 28, 273 (2010).

${ }^{31}$ H. Zeng, J. Li, J. P. Liu, Z. L. Wang, and S. Sun, Nature (London) 420, 395 (2002).

${ }^{32}$ X. Rui, J. E. Shield, Z. Sun, Y. Xu, and D. J. Sellmyer, Appl. Phys. Lett. 89, 122509 (2006).

${ }^{33}$ Y. Zhang, M. J. Kramer, C. Rong, and J. P. Liu, Appl. Phys. Lett. 97, 032506 (2010).

${ }^{34}$ R. Coehoorn, D. B. de Mooij, and C. J. de Waard, J. Magn. Magn. Mater. 80, 101 (1989).

${ }^{35}$ E. F. Kneller and R. Hawig, IEEE Trans. Magn. 27, 3588 (1991).

${ }^{36}$ R. Skomski and J. M. D. Coey, Phys. Rev. B 48, 15812 (1993).

${ }^{37}$ Y. Liu, T. George, R. Skomski, and X. Z. Li, Appl. Phys. Lett. 99, 172504 (2011).

${ }^{38}$ D. J. Sellmyer and Z. S. Shan, in Science and Technology of Nanostructured Magnetic Materials, edited by G. Hadjipanayis and G. A. Prinz (Plenum, New York, 1991), p. 151. 